\title{
The Lives, Friendship and Separation of Latency Girls: Loss and Development Depicted in the Film "The World of Us"
}

\author{
Song-li Ahn ${ }^{1}$ and Sookyung Lee ${ }^{2}$ \\ ${ }^{1}$ National Health Insurance Service Ilsan Hospital, Goyang, Korea \\ ${ }^{2}$ Sowoon Psychiatric Clinic, Seongnam, Korea
}

The film "The World of Us (2016)" shows the acquisition and loss of friendship that occur in the process of interpersonal shifts in latency school girls. Connection to the peer group helps compensate for the latency child's loss of parent-child intimacy and the ensuing feelings of loneliness. The protagonists realize that the relationship is not for retaliation or for victory, but for playing together. However the reality that lies in front of them will not be so easy. Watching this film reminds one of childhood.

Key Words: Latency period; Psychological; Bullying; Aggression; Peer group; Interpersonal relations; Friend; Child development.

Received: March 16, 2021 / Accepted: March 16, 2021

Address for correspondence: Sookyung Lee, Sowoon Psychiatric Clinic, 2 Seohyeon-ro 210beon-gil, Bundang-gu, Seongnam 13591, Korea Tel: +82-31-703-7820, Fax: +82-31-703-7811, E-mail: Isk15@hanmail.net

The film "The World of Us (2016)" shows the acquisition and loss of friendship that occur in the process of interpersonal shifts in latency school girls (Fig. 1). This film won awards at the 37th Blue Dragon Awards, the 36th Korean Association of Film Critics Awards, and the 25th Buil Film Awards in 2016, and at the 53rd Baeksang Arts Awards and the 4th Wild Flower Film Awards in 2017. In addition, it was officially invited to the 66th Berlin International Film Festival, and won the grand prize at the 56th Zlin International Children and Youth Film Festival.

The director Ga-eun Yoon has also received attention for her short films "Guest (2011)" and "Sprout (2013)," and was invited to the 64th Berlin International Film Festival. She has carefully depicted the experiences of women during the family dissolution and loss, from "Guests" to her latest work, "The House of Us (2019)."

"The World of Us" features 10-years-old Sun (Soo-in Choi) who is an outcast at school despite her efforts to make friends and is bullied by Bora (Seo-yeon Lee). On the day of the vacation ceremony she meets Jia (Hye-in Seol) who has moved to her grandmother's house, and they soon form a close bond and share secrets. When Jia later attempts to get into Bora's group at school and starts to distance herself from Sun. Sun and Jia end up hurting each other.

This is an Open Access article distributed under the terms of the Creative Commons Attribution Non-Commercial License (https://creativecommons.org/licenses/by-nc/4.0) which permits unrestricted non-commercial use, distribution, and reproduction in any medium, provided the original work is properly cited.
A positive relationship with parents and the past history of strong ties between parents and children becomes an autonomous function and a tool for social expansion in latency children [1]. The second separation-individualization is a rework of the psychological structure in which a new object of love is found and experienced as an autonomous subject [2]. As latency children become more self-determined and self- responsible, they begin to feel emptiness and loneliness. Gradual de-idealization of parents begins in latency and accelerates rapidly to preadolescence [3]. Connection to the peer group helps compensate for the latency child's loss of parentchild intimacy and the ensuing feelings of loneliness [1]. The latency child begins to adapt to the needs, expectations, and reactions of his or her peers, which are very different from those of parents and siblings [4].

As the latency child's dependency on the parents decreases, membership in same-sex friendships and groups provides a powerful compensatory sense of community and connection [5]. Play becomes gender-segregated [6]. Girls tend to form factions and can be mean-spirited toward "outsiders" $[1,7]$ "Best friend" relationships are eagerly pursued [1]. Peer cliques are common and provide an important source of group socialization, deeply influencing the preadolescent's behavior, style, and attitudes [7,8].

Boys tend to be action-oriented, and often engage in behavior involving danger and overt conflict. Girls tend toward greater personal intimacy but may employ relational aggres- 


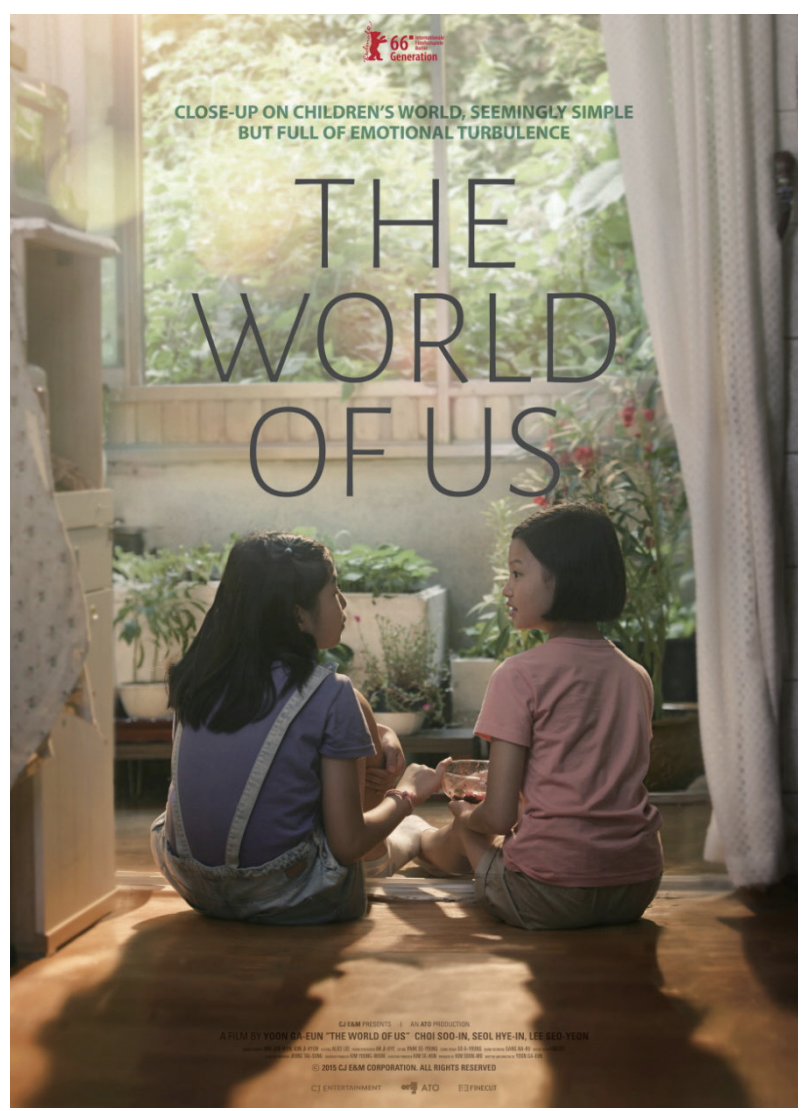

Fig. 1. Poster of the film "The World of Us."

sion [9], which appears in the form of teasing, excluding, and indirect manipulative aggression. In preadolescents, peer victimization mediates links between negative self-perceptions and increased internalizing problems $[4,7,10]$.

Several scenes in the film involve a dodgeball. In dodgeball, one is surrounded by opponents on all sides. There is no place to hide, and one must defend against attacks from all sides. In addition, the child who the ball has hit can attack the opponent. Dodgeball is a game in which victims fight each other. In some ways, Sun and Jia are in a position to defend against attacks from peers. Both Sun and Jia are outcasts and attack each other.

Sun is being bullied for unknown reasons. The Bora clique bullies her by saying that she is poor or smells bad. Sun is small and plays in the playground or in the water, reminding us of how preschooler play. Sun kindly invites Jia home, and she cooks kimchi fried rice for them to eat together. She shares balsam with Jia to color fingernails with balsam, rather than with manicure. She seems to take care of Jia, like a mother. Sun is close to her mother, and she always takes care of her younger brother Yoon (Min-joon Kang). Her peers move on to preadolescence, but she remains the same.

Jia was bullied at school before she was transferred because her parents divorced in her first grade of elementary school. She lies that her mother is living in the United Kingdom and tries to hide her mother's absence. Adventurous and grandiose fantasies, including the family romance, serve to compensate for the loss of ideal parents and fears of inadequacy as the child experiences the difficulties of latency [1].

Jia engages in indirect sadistic behavior, such as spreading rumors that Sun's financial circumstances are poor, and Sun's father is an alcoholic. Her relationship with her own parents is unstably internalized, and this interferes with her ability to understand and sympathize with others [11]. Jia does not have available parents who can help her to deal with difficult emotions [12]. Her behavior shows how sadness can lead to anger and sadistic behavior.

Why does the friendship between Sun and Jia deteriorate? One possible reason may be Jia's jealousy over the loving relationship between Sun's mother and Sun. The relationship between the two girls becomes complicated, when other characters (Sun's mother and Bora) come into the picture. Bora's group invites Jia into their circle. For this group relationships and affiliations are fiercely connected to survival. For those who want to make new friends, old friendships can be easily discarded. The hearts of the audience watching this process of betrayal also fall into sorrow. Jia removes herself from Sun's influences, which had possibly functioned as a regression to her relationship with her parents, and turns to other peers for friendship and a sense of belonging. This could be viewed as a child's struggle against regression.

Adults are not featured heavily in the film. Sun's mother leaves her children at work, but she has intense moral goodness and is a warm mother who protects her children. Sun's father is in conflict with his father, who is a poor worker. He abuses alcohol, but is not indifferent to parenting and remembers his daughter's friend's name. The teacher is not discriminated against because of academic or family circumstances, and is willing to intervene sensibly. However, only after Sun steals money from her mother and Sun gets into a physical fight with Jia, adults focused on Sun and Jia.

Bora is a powerful figure. She makes the rules and is given authority by her friends. She uses gossip to socially exclude Sun and Jia. Those who do not agree with her methods face the threat of isolation and loneliness. Thus, latency children are willing to join in to survive in their peer group. For this purpose, they conform, exclude others, and share and produce gossip. They are willing to use cruelty for recognition and power.

What could be the solution for a child experiencing peer loss? In the film, Yoon's word 'When do we play? I just want to play.' eventually causes Sun to change her view of her relationship with Jia and to gain better understanding of conflict and ambivalence. If Sun hurts and harasses each other, 
she will lose a friend whom she trusts and depends on. Sun approaches Jia first to mend their relationship. They both come to realize that their relationship is not for retaliation or for victory, but for playing together, but the reality that lies in front of them will not be so easy. The Korean title of the film is 'Woorideul', it means "us". The "us" is embracing, but could also be hostile or exclusive when it means "you" or "outsider" versus "us" and "insider."

Watching "The World of Us" reminds the audience of childhood. We had to join a new group every new semester, and had to guard our reputations. This film forces us to recall heartbreaking memories, and these forgotten experience can also help latency children understand and empathize with inevitable miseries.

\section{Acknowledgments}

None.

\section{Conflicts of Interest}

The authors have no potential conflicts of interest to disclose.

\section{Author Contributions}

Conceptualization: Song Ii Ahn, Sookyung Lee. Data curation: Song Ii Ahn. Formal analysis: Song Ii Ahn, Sookyung Lee. Funding acquisition: Song Ii Ahn. Investigation: Song Ii Ahn, Sookyung Lee. Methodology: Song Ii Ahn, Sookyung Lee. Project administration: Sookyung Lee. Resources: Song Ii Ahn. Software: Song Ii Ahn. Supervision: Sookyung Lee. Validation: Song Ii Ahn, Sookyung Lee. Visualization: Song Ii Ahn. Writing —original draft: Song Ii Ahn. Writing—review and editing: Song Ii Ahn, Sookyung Lee.

\section{ORCID iDs}

\section{Song Ii Ahn}

https://orcid.org/0000-0003-2418-736X

Sookyung Lee
https://orcid.org/0000-0001-8940-093X

\section{REFERENCES}

1) Gilmore KJ, Meersand P. Normal child and adolescent development: a psychodynamic primer. Washington DC: American Psychiatric Publishing;2014. p.156-162.

2) Blos P. The adolescent passage: developmental issues. New York: International Universities Press;1979.

3) Allen JP, Land D. Attachment in adolescence. In: Cassidy J, Shaver PR, editors. Handbook of attachment: theory, research, and clinical applications. New York: The Guilford Press;1999. p.319-333.

4) Rubin KH, Bukowski WM, Parker JG. Peer interactions, relationships, and groups. In: Damon W, Lerner RM, Eisenberg N, editors. Handbook of child psychology, 6th edition. Hoboken, New Jersey: Wiley \& Sons;2007. p.571-645.

5) Knight R. The process of attachment and autonomy in latency: a longitudinal study of ten children. Psychoanal Study Child 2005; 60:178-210.

6) Friedman RC, Downey JI. Sexual differentiation of behavior: the foundation of a developmental model of psychosexuality. J Am Psychoanal Assoc 2008;56:147-175.

7) Harris JR. Where is the child's environment? A group socialization theory of development. Psychol Rev 1995;102:458-489.

8) Adler PA, Adler P. Dynamics of inclusion and exclusion in preadolescent cliques. Soc Psychol Q 1995;58:145-162.

9) Simmons R. Odd girl out: the hidden culture of aggression in girls. Boston, MA: Houghton Mifflin Harcourt;2002.

10) Troop-Gordon W, Ladd GW. Trajectories of peer victimization and perceptions of the self and schoolmates: precursors to internalizing and externalizing problems. Child Dev 2005;76:1072-1091.

11) Jemerin JM. Latency and the capacity to reflect on mental states. Psychoanal Study Child 2004;59:211-239.

12) Colarusso CA. Child and adult development: a psychoanalytic introduction for clinicians. New York: Plenum Press;1992. 